\title{
SURGERY FOR "DOUBLE JEOPARDY” IN THE LUNG: LUNG CANCER AND MULTIPLE LUNG METASTASES OF PAPILLARY CARCINOMA OF THE THYROID
}

\author{
Yukihito Saito, MD, ${ }^{\mathrm{a}}$ Hideyasu Omiya, MD,${ }^{\mathrm{a}}$ Yuzo Shomura, MD, ${ }^{\mathrm{a}}$ Hiroji Imamura, MD, ${ }^{\mathrm{a}}$ and Akiharu Okamura, MD, ${ }^{\mathrm{a}}$ \\ Osaka, Japan
}

We have performed surgery on several patients with primary lung cancer and a synchronous/metachronous cancer of another organ. However, we have never before treated a patient with primary lung cancer and multiple synchronous metastases from thyroid cancer in both lungs. Although patients with papillary thyroid carcinoma have a favorable long-term prognosis, the subgroup who have distant metastases are known to have a worse prognosis. ${ }^{1}$ It is difficult to plan the treatment of patients in such a "double jeopardy" situation.

We describe our first experience treating a patient with double jeopardy in the lung: primary lung cancer and multiple lung metastases of papillary carcinoma of the thyroid.

Clinical summary. A 68-year-old woman had a mass on a follow-up chest x-ray film after surgery for thyroid papillary carcinoma. Bilateral miliary nodular lesions were observed on chest computed tomography at the time of admission. The patient had undergone total thyroidectomy for papillary carcinoma of the thyroid 5 years earlier. A biopsy specimen at bronchoscopy revealed a poorly differentiated adenocarcinoma of the lung. However, we could not determine whether the

From the Department of Thoracic and Cardiovascular Surgery, ${ }^{\mathrm{a}}$ Division of Surgical Pathology, ${ }^{\mathrm{b}}$ Kansai Medical University, Moriguchi, Japan.

Received for publication April 27, 1999; accepted for publication June 3, 1999.

Address for reprints: Yukihito Saito, MD, 10-15 Fumizonocho, Moriguchi, Osaka 570-8507, Japan.

J Thorac Cardiovasc Surg 1999;118:747-8

Copyright (C) 1999 by Mosby, Inc.

$0022-5223 / 99 \$ 8.00+0 \quad \mathbf{1 2 / 5 4 / 1 0 0 6 1 3}$ bilateral multiple small nodules were metastases from the lung cancer or the thyroid carcinoma. If the miliary micronodules were thyroid carcinoma metastases, the clinical TNM stage of lung cancer would be T2 N0 M0.

We knew that patients with lung metastases from thyroid carcinoma have a relatively good prognosis, with an estimated mean survival of $77 \%$ at 8 years. Therefore this patient's life-limiting factor was the lung cancer, not the thyroid carcinoma metastases. We recommended that she undergo surgery for lung cancer. However, because she had no symptoms, she refused both the operation and anticancer chemotherapy. Seven months later, she decided to undergo surgery because she had bloody sputum. If the micronodules were metastases from adenocarcinoma of the lung, the disease would be too advanced for lung resection. Therefore some micronodules were sampled by open lung biopsy through a minithoracotomy approach at the time of operation. Pathologic examination showed that these micronodules were metastases from papillary carcinoma of the thyroid. Mediastinal lymph nodes were also sampled through the minithoracotomy and were negative for malignancy. No pleural dissemination was observed. We therefore decided to perform a right upper lobectomy.

A lung cancer measuring $34 \times 24 \mathrm{~mm}$ was located at S2 of the right lung. We completed the right upper lobectomy. Pathologic TNM staging was stage II. Pathologic examination of the resected specimens demonstrated a marked contrast in the growth characteristics of the 2 tumors. In the lung cancer, Ki-67 antigen expression was observed in many tumor cells. By flow cytometric cell cycle analysis, the DNA histogram was aneuploid and the $\mathrm{S}+\mathrm{G} 2+\mathrm{M}$ phase fraction was $52 \%$. In contrast, the lung metastases from the papillary 


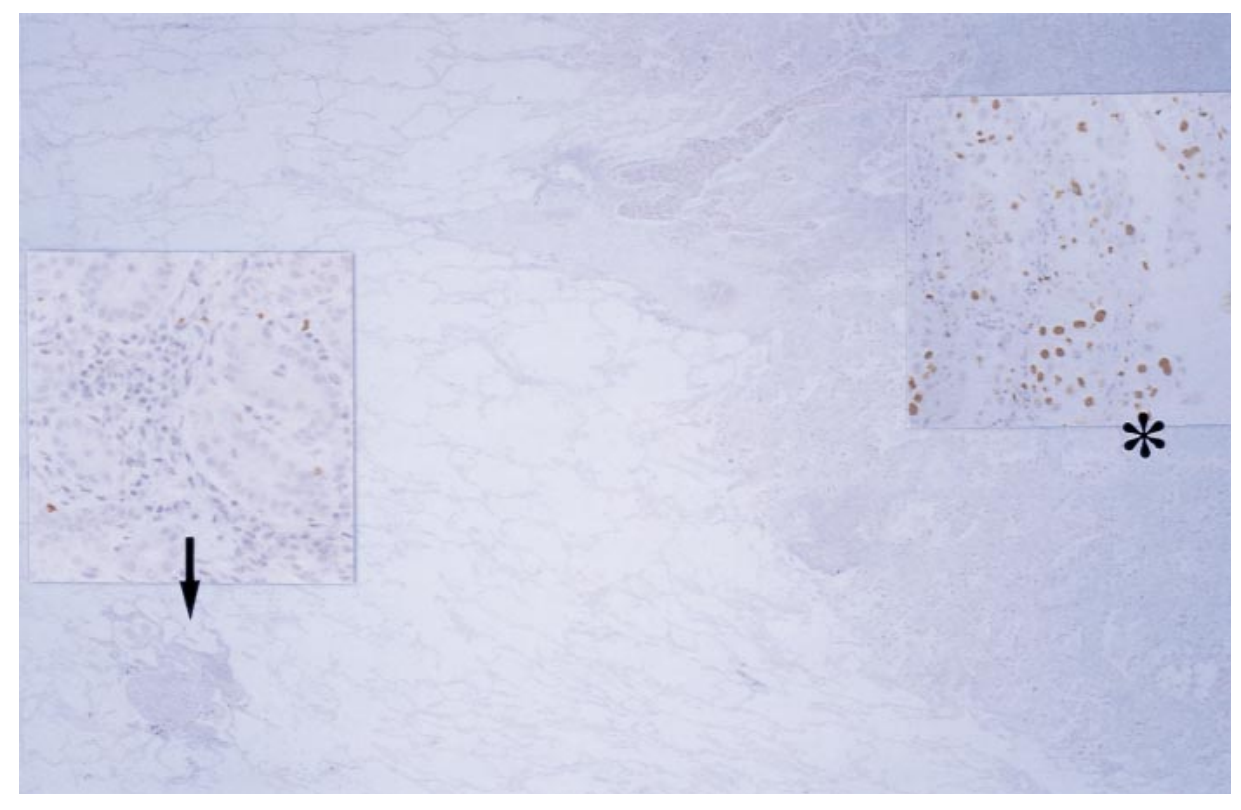

Fig 1. Histologic findings: Ki-67 antigen expression was observed in many tumor cells in the lung cancer region (asterisk). In contrast, the lung metastases from the papillary thyroid carcinoma (arrow) had an extremely low level of Ki-67 antigen expression.

thyroid carcinoma had an extremely low level of Ki-67 antigen expression, a diploid DNA histogram, and a small growth fraction (Fig 1).

Comment. Lobectomy for primary lung cancer with coexisting metastases in the same lung has to our knowledge never been reported in the literature. Although papillary thyroid carcinoma is associated with a favorable long-term survival, the presence of metastases in distant sites other than the lung, such as bone, brain, and liver, is an important unfavorable prognostic indicator. ${ }^{2}$ The mortality rate rises after age 70 and falls before age 40 years. However, even without specific treatment, pulmonary metastases may follow a very slow course. The miliary variety of pulmonary metastases paradoxically carries a favorable prognosis. In our patient, Ki-67 antigen expression and growth fraction in the micronodular pulmonary metastases was extremely low, in contrast to the lung cancer. Micronodular metastases occur more frequently in papillary thyroid carcinoma than in follicular thyroid carcinoma. The prognosis of micronodular metastases is favorable, with a $77 \%$ likelihood of survival at 8 years. ${ }^{3}$ Our patient was 68 years old and had micronodular metastasis from papillary carcinoma. We recommended that she undergo surgery for her lung cancer. However, she refused surgical treatment as well as anticancer chemotherapy, and the lung cancer doubled in size in 7 months after the diagnosis. The actuarial 2-year survival of advanced non-small cell lung cancer is $7.4 \%$ even in patients who receive platinum-based anticancer chemotherapy. ${ }^{4}$ We again recommended surgery, and she finally agreed to undergo the lung operation. Three years after the operation, she is free of symptoms and enjoys a good quality of life. To date, chest computed tomography reveals no recurrence of the lung cancer and no progression of the remaining micronodular thyroid carcinoma metastases.

\section{REFERENCES}

1. Ashok RS, Jatin PS, Thom RL. Risk group stratification and prognostic factors in papillary carcinoma of thyroid. Ann Surg Oncol 1996;3:534-8.

2. Dario C, Domencio R, Giorgio S, Guido M, Adriano F, Maria EG, et al. Different features of pulmonary metastases in differentiated thyroid cancer: natural history and multivariate statistical analysis of prognostic variables. J Nucl Med 1993;34:1626-31.

3. Jean-Piere M, Jean-Claude S, Henri G, Gerard G, Francoise AL, Francoise B. Pulmonary metastases in differentiated thyroid carcinoma. Cancer 1984;53:982-92.

4. Sculier JP, Paesmans M, Libert P, Bureau G, Dabouis G, Thiriaux $\mathrm{J}$, et al. Long-term survival after chemotherapy containing platinum derivatives in patients with advanced unresectable nonsmall cell lung cancer. Eur J Cancer 1994;30A:1342-7. 